\title{
High stathmin 1 expression is associated with poor prognosis and chemoradiation resistance in esophageal squamous cell carcinoma
}

\author{
SHIGEMASA SUZUKI ${ }^{1 *}$, TAKEHIKO YOKOBORI ${ }^{1 *}$, BOLAG ALTAN $^{2 *}$, KEIGO HARA $^{1}$, \\ DAIGO OZAWA $^{1}$, NARITAKA TANAKA ${ }^{1}$, MAKOTO SAKAI ${ }^{1}$, AKIHIKO SANO ${ }^{1}$, MAKOTO SOHDA ${ }^{1}$, \\ HALIN BAO $^{1}$, MINORU FUKUCHI ${ }^{1}$, TATSUYA MIYAZAKI ${ }^{1}$, KYOICHI KAIRA ${ }^{2}$, \\ TAKAYUKI ASAO ${ }^{3}$ and HIROYUKI KUWANO ${ }^{1}$ \\ Departments of ${ }^{1}$ General Surgical Science, and ${ }^{2}$ Oncology Clinical Development, Gunma University, \\ Graduate School of Medicine, Maebashi, Gunma 371-8511; ${ }^{3}$ Big Data Center for Integrative Analysis, \\ Gunma University Initiative for Advance Research (GIAR), Gunma, Japan
}

Received January 3, 2017; Accepted February 24, 2017

DOI: 10.3892/ijo.2017.3899

\begin{abstract}
Stathmin 1 (STMN1) is a major cytosolic phosphoprotein regulating microtubule dynamics, thereby playing an important role in cancer progression and resistance to microtubule-binding anticancer agents. We assessed the prognostic significance of STMN1 expression and STMN1-associated resistance to docetaxel and radiation in esophageal squamous cell carcinoma (ESCC) patients. STMN1 expression was evaluated by immunohistochemistry in 172 surgical specimens. The association of STMN1 expression with chemoradiation resistance using docetaxel was examined by comparing expression in 15 biopsy specimens obtained before neoadjuvant therapy to histological grades of post-therapy surgically resected tumors. We also evaluated the effects of STMN1 on sensitivity to docetaxel and radiation in ESCC cell lines. High STMN1 immunoexpression was significantly associated with tumor depth, lymph node metastasis, lymphatic invasion and venous invasion. Survival rates were significantly lower in ESCC patients with high STMN1 expression than in those with low STMN1 expression. Multivariable analysis showed that high STMN1 expression was an independent factor for
\end{abstract}

Correspondence to: Dr Takehiko Yokobori, Department of General Surgical Science, Gunma University, Graduate School of Medicine, 3-39-22 Showa-machi, Maebashi, Gunma 371-8511, Japan E-mail: bori45@gunma-u.ac.jp

*Contributed equally

Abbreviations: ESCC, esophageal squamous cell carcinoma; CRTs chemoradiotherapies; STMN1, stathmin 1; 5-FU, 5-fluorouracil; VEGF, vascular endothelial growth factor A; HIF-1 $\alpha$, hypoxiainducible factor 1 alpha subunit

Key words: radiation resistance, anti-microtubular drugs, gastrointestinal tract, oncoprotein 18 , prognostic markers poor survival. High STMN1 expression was also associated with poor response to neoadjuvant chemoradiotherapy using docetaxel. Knockdown of STMN1 expression enhanced ESCC cell line sensitivity to docetaxel and radiation. STMN1 appears critical for ESCC invasiveness and predicts an unfavorable prognosis in ESCC.

\section{Introduction}

Esophageal squamous cell carcinoma (ESCC) is a highly aggressive malignancy with a significant mortality rate $(1,2)$. Despite improvements in the surgical management of ESCC and development of useful chemotherapies and chemoradiotherapies (CRTs), the prognosis of patients with advanced disease remains poor (3-5). Furthermore, the identification of novel therapeutic targets is essential for individual curative adjuvant or neoadjuvant therapies.

Stathmin 1 (STMN1) is a major cytosolic phosphoprotein that regulates microtubule dynamics by preventing tubulin polymerization and promoting microtubule destabilization (6). STMN1 is highly expressed in multiple human malignancies and is therefore also known as oncoprotein 18. STMN1 expression correlates with tumor progression and poor prognosis in various cancers (7-17) including ESCC (18). These studies indicated that STMN1 is a fundamental cancer-associated gene and a potential target for the diagnosis and treatment of cancers, including ESCC. However, the exact significance of STMN1 in tumor progression and therapeutic resistance has not yet been elucidated in ESCC patients treated with CRT.

The expression of STMN1 is known to be functionally linked to chemosensitivity to microtubule-stabilizing agents such as taxanes, which are widely used anticancer agents. Inhibiting STMN1 expression enhances chemosensitivity to paclitaxel in osteosarcoma cells (19) and ESCCs (20) in vitro, while the overexpression of STMN1 decreases breast cancer cell sensitivity to paclitaxel and vinblastine (7). In Japan, docetaxel is considered a key drug in ESCC chemotherapy along with cisplatin plus 5-fluorouracil (5-FU) $(21,22)$. In addition, radiation therapy with or without chemotherapy has 
been established as one of the more effective treatments for ESCC (23) and STMN1 was reported to increase the radiation resistance in lung cancer cells (24). The identification of novel predictive factors for therapeutic responses to docetaxel and radiation is essential for ESCC management because drug resistance leads to poor clinical outcomes.

The aim of the present study was to evaluate the prognostic significance of STMN1 expression in ESCC by examining the associations of tumor expression levels with various clinicopathological parameters, particularly 5-year diseasespecific and overall survival. Moreover, we evaluated the role of STMN1 in chemoradiation resistance in biopsied ESCC tissues and ESCC cell lines.

\section{Materials and methods}

Patients and samples. To evaluate the clinicopathological significance of STMN1 in ESCC, surgical specimens were obtained from 172 ESCC patients (158 men and 14 women; 40-83 years old; mean age, 63.4 years) who had undergone potentially curative surgery at the Gunma University Department of General Surgical Science between 1997 and 2010. All patients provided written informed consent. None had received radiotherapy or chemotherapy prior to surgery; no patient displayed hematogenic metastases at the time of surgery. The median follow-up period for survivors was 32.6 (0.7-128) months. The pathological features of the specimens were classified based on the 6th edition of the TNM classification of the International Union against Cancer (25).

For examination of the association of STMN1 expression with chemoresistance to docetaxel in vivo, pretreatment biopsy specimens were obtained from 15 patients (12 men and 3 women; 55-76 years old; mean age, 65.3 years) who had received neoadjuvant CRT, including a docetaxel protocol, followed by tumor resection surgery at the Gunma University Department of General Surgical Science between 2005 and 2008. For docetaxel combination CRT, external radiotherapy was delivered by a 2-field technique using a 10-MV photon beam at 2 Gy per fraction per day, 5 fractions per week, for a total of $40 \mathrm{~Gy}$. Concurrent chemotherapy consisted of $7 \mathrm{mg} / \mathrm{m}^{2}$ docetaxel intravenously administered for $1 \mathrm{~h}$ before radiotherapy on days $1,8,15$ and 22 . Treatment, toxicity, and response evaluation details were previously described (26).

Immunohistochemistry. Prior to the analysis, resected surgical specimens and biopsy specimens were fixed with $10 \%$ formaldehyde, embedded in paraffin blocks, cut into $4-\mu \mathrm{m}$ thick sections and mounted onto glass slides. STMN1 expression was assessed by immunohistochemistry using a standard streptavidin-biotin peroxidase complex method as previously described (27). Each $4-\mu \mathrm{m}$ section was then incubated at $4^{\circ} \mathrm{C}$ overnight with mouse anti-STMN1 monoclonal antibodies (Santa Cruz Biotechnology, Santa Cruz, CA, USA) diluted 1:50 in phosphate-buffered saline (PBS) containing $1 \%$ bovine serum albumin (BSA) and primary mouse anti-Ki-67 monoclonal antibody (clone MIB-1; 1:40 dilution; Dako, Glostrup, Denmark). For negative controls, the specific primary antibody was replaced with PBS. Immunolabeling was visualized using the chromogen 3,3'-diaminobenzidine tetrahydrochloride applied as a $0.02 \%$ solution containing $0.005 \%$ hydrogen peroxide in $50 \mathrm{mM}$ ammonium acetate-citrate acid buffer (pH 6.0). Sections were then lightly counterstained in Mayer's hematoxylin and mounted.

Evaluation of immunostaining. For assessing STMN1 immunoreactivity, the product of cytoplasmic intensity and quantity was calculated for each section as previously described (28). The intensity was graded as 0 , negative, 1 , low, 2, medium, or 3 , high, and the quantity as 0 , no expression, 1 , positivity in $<1 \%$ of cells, 2 , positivity in $1-9 \%, 3$, positivity in $10-50 \%$, or 4 , positivity in $>50 \%$. The ESCC patients were divided into two groups according to the mean STMN1 immunoreactivity score of the surgical specimens. The labeling index was calculated as the percentage of nuclear-stained cells for each section on the basis of $\sim 1,000$ tumor cell nuclei and was counted at the site with the maximum number of positive nuclei in the whole tumor. The ESCC patients were classified as high or low based on the ROC-derived Ki-67 labeling index cut-off value.

Evaluation of therapeutic response to docetaxel combination CRT in surgically resected specimens. The pathological evaluation of surgically resected tumor samples from patients receiving CRT (including docetaxel) was conducted by two experienced pathologists who were blinded to the clinical responses. The histopathological response to neoadjuvant treatment was divided into four grades $(0,1,2$ and 3$)$ according to the guidelines of the Japan Esophageal Society (29). The pathological viability of the residual tumor cells was assessed as follows: grade 3, histological fibrosis with or without inflammation extending through the different layers of the esophageal wall, but no viable residual tumor cells; grade 2, less than one-third of residual tumor cells were viable; grade 1 , more than one-third of residual tumor cells were viable; and grade 0 , no therapeutic effect.

Cell lines. Four human ESCC cell lines (TE-1, TE-8, TE-15 and KYSE140) and a non-malignant human esophageal epithelial cell line (HET1A) were used to examine the associations of STMN1 expression level with both docetaxel and radiation sensitivity in vitro. All ESCC cell lines were cultured in RPMI-1640 medium (Sigma-Aldrich, St. Louis, MO, USA) supplemented with $10 \%$ fetal bovine serum (FBS) and antibiotics (100 U/ml penicillin and $100 \mu \mathrm{g} / \mathrm{ml}$ streptomycin) and cultured in a humidified $5 \% \mathrm{CO}_{2}$ incubator at $37^{\circ} \mathrm{C}$. These cells were not cross-contaminated with other cell lines by STR-PCR.

siRNA and transfections. An STMN1-specific siRNA (Bonac Corp., Kurume, Japan) was mixed with $0.4 \%$ Lipofectamine RNAiMAX (Invitrogen, Carlsbad, CA, USA) in 6-well flatbottom microtiter plates and incubated. TE- 8 and KYSE140 ESCCs in $2 \mathrm{ml}$ of RPMI-1640 medium were then seeded on microtiter plates and incubated in a humidified $5 \% \mathrm{CO}_{2}$ incubator at $37^{\circ} \mathrm{C}$ for $24 \mathrm{~h}$ before analysis. Knockdown was confirmed at the protein level by western blot analysis.

Western blot analysis. Total protein was extracted using PRO-PREP protein extraction solution (Intron Biotechnology, Inc., Kyungki-Do, Korea). Total protein was separated by sodium dodecyl sulfate-polyacrylamide gel electrophoresis 
(SDS-PAGE) using Bis-Tris gels and was transferred to membranes. After membranes were blocked with 5\% skim milk, STMN1 protein was detected by immunoblotting with anti-STMN1 rabbit polyclonal antibodies (Cell Signaling Technology, Danvers, MA, USA) and vascular endothelial growth factor A (VEGF) with an anti-VEGF rabbit monoclonal antibody (Abcam, Cambridge, UK) diluted 1:1,000. An antiHSC70 antibody (1:500; Santa Cruz Biotechnology) served as a gel loading control. Specific signals were detected using the ECL Prime Western blotting detection system (GE Healthcare, Chicago, IL, USA) and quantified by an ImageQuant LAS 4000 instrument (GE Healthcare).

Docetaxel sensitivity assay. The WST- 8 test from the Cell Counting kit-8 (CCK-8; Dojindo Laboratories, Kumamoto, Japan) was used to evaluate the docetaxel sensitivity of tumor cells. At $48 \mathrm{~h}$ after transfection, TE-8 and KYSE140 cells were seeded into 96-well plates at $1 \times 10^{4}$ cells/well in $100 \mu \mathrm{l}$ of culture medium for $24 \mathrm{~h}$ prior to drug exposure. After $24 \mathrm{~h}$ of pre-incubation, cells were treated with various concentrations of docetaxel for $24 \mathrm{~h}$. Following drug exposure, $10 \mu \mathrm{l}$ of WST-8 reagent solution was added to each well, and cells were incubated for an additional $2 \mathrm{~h}$ at $37^{\circ} \mathrm{C}$ in an incubator. Cell viability was estimated by the optical density values at $450 \mathrm{~nm}$, with the reference wavelength set at $650 \mathrm{~nm}$.

Radiation sensitivity assay. Radiation sensitivity was evaluated by the colony formation assay. TE8 cells ( 400 cells/well) treated with siRNAs were seeded in 6-well plates. After $24 \mathrm{~h}$ of pre-incubation, cells were $\mathrm{X}$-irradiated at $0,2,4,6$, or $8 \mathrm{~Gy}$ and incubated at $37^{\circ} \mathrm{C}$ for 10 days to form colonies. Cells were fixed and stained with $2 \%$ crystal violet in $100 \%$ ethanol. Colonies were manually counted. The fraction of cells that survived treatment was calculated relative to non-treated controls.

Statistical analysis. Group differences in means and proportions were evaluated using the Student's t-test, the Chi-square test, or repeated-measures ANOVA as appropriate. Kaplan-Meier survival curves were generated, and statistical significance was determined using the log-rank test. Univariate and multivariate survival analyses were conducted using the Cox proportional hazards regression model. All statistical analyses were performed using JMP software (SAS Institute, Inc., Cary, NC, USA).

\section{Results}

Association of STMN1 expression with clinicopathological features of ESCC. The immunoexpression of STMN1 was stronger in the marginal regions of primary ESCCs than in the main tumor or surrounding normal tissues (Fig. 1A and B). When classified according to the mean STMN1 immunoreactivity score, 75 ESCC samples (43.6\%) were defined as having low STMN1 expression (Fig. 1C), while 97 ESCC samples (56.4\%) were defined as having high STMN1 expression (Fig. 1D).

STMN1 expression in relation to nine patient clinicopathological characteristics is listed in Table I. High STMN1 expression was significantly associated with progression of
Table I. Association of stathmin 1 (STMN1) expression with clinicopathological features in 172 esophageal squamous cell carcinoma (ESCC) patients.

\begin{tabular}{|c|c|c|c|}
\hline \multirow[b]{2}{*}{ Factors } & \multicolumn{2}{|c|}{ STMN1 expression } & \multirow[b]{2}{*}{ P-value } \\
\hline & $\begin{array}{l}\text { Low } \\
(\mathrm{n}=75)\end{array}$ & $\begin{array}{l}\text { High } \\
(\mathrm{n}=97)\end{array}$ & \\
\hline \multicolumn{4}{|l|}{ Gender } \\
\hline Male & 69 & 89 & \multirow[t]{2}{*}{0.953} \\
\hline Female & 6 & 8 & \\
\hline $\begin{array}{l}\text { Age (years) } \\
(\text { mean } \pm \mathrm{SD})\end{array}$ & $62.0 \pm 8.8$ & $64.4 \pm 7.6$ & 0.084 \\
\hline \multicolumn{4}{|l|}{ Tumor depth } \\
\hline $\mathrm{T} 1$ & 43 & 29 & \multirow[t]{4}{*}{$0.001^{\mathrm{a}}$} \\
\hline $\mathrm{T} 2$ & 6 & 14 & \\
\hline $\mathrm{T} 3$ & 23 & 53 & \\
\hline $\mathrm{T} 4$ & 3 & 1 & \\
\hline \multicolumn{4}{|c|}{ Lymph node metastasis } \\
\hline No & 36 & 27 & \multirow[t]{2}{*}{$0.007^{\mathrm{a}}$} \\
\hline $\mathrm{N} 1$ & 39 & 70 & \\
\hline \multicolumn{4}{|c|}{ Distant metastasis } \\
\hline M0 & 65 & 75 & \multirow[t]{2}{*}{0.114} \\
\hline M1 & 10 & 22 & \\
\hline \multicolumn{4}{|c|}{ Lymphatic invasion } \\
\hline Negative & 21 & 7 & \multirow[t]{2}{*}{$<0.001^{\mathrm{a}}$} \\
\hline Positive & 54 & 90 & \\
\hline \multicolumn{4}{|l|}{ Venous invasion } \\
\hline Negative & 34 & 14 & \multirow[t]{2}{*}{$<0.001^{\mathrm{a}}$} \\
\hline Positive & 41 & 83 & \\
\hline \multicolumn{4}{|l|}{ Stage } \\
\hline I & 30 & 11 & \multirow{4}{*}{$<0.001^{\mathrm{a}}$} \\
\hline II & 19 & 35 & \\
\hline III & 16 & 29 & \\
\hline IV & 10 & 22 & \\
\hline
\end{tabular}

Ki-67 labeling index

$\begin{array}{llll}(\text { mean } \pm \mathrm{SD}) & 35.8 \pm 18.4 & 45.8 \pm 17.5 & 0.0039^{\mathrm{a}}\end{array}$

${ }^{\mathrm{a}} \mathrm{P}<0.05$.

tumor depth $(\mathrm{P}=0.001)$, lymph node metastasis $(\mathrm{P}=0.007)$, lymphatic invasion $(\mathrm{P}<0.001)$, venous invasion $(\mathrm{P}<0.001)$, tumor stage $(\mathrm{P}<0.001)$ and proliferation maker Ki-67 labeling index $(\mathrm{P}=0.0039)$.

STMN1 expression and postoperative survival in ESCC patients. The 5-year disease-specific survival rate was significantly reduced in ESCC patients with high STMN1 expression compared to those with low STMN1 expression (49.5 vs. $73.9 \%$, respectively; $\mathrm{P}=0.002$; Fig. 1E). The 5 -year overall survival rate was also significantly reduced in ESCC patients with high STMN1 expression compared to those with low STMN1 expression (43.6 vs. $70.2 \%$, respectively; $\mathrm{P}=0.001$; 
A

B
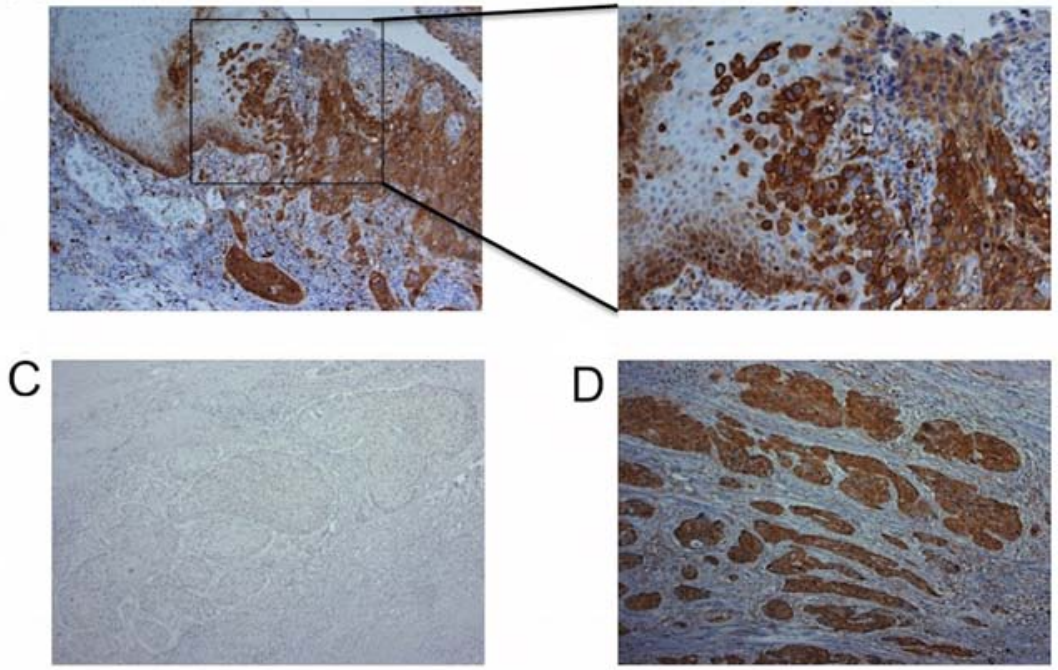

E

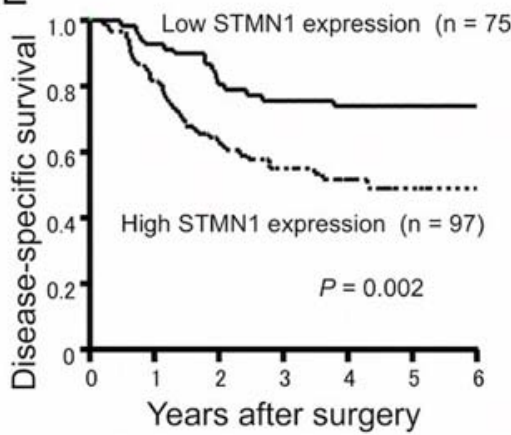

$\mathrm{F}$

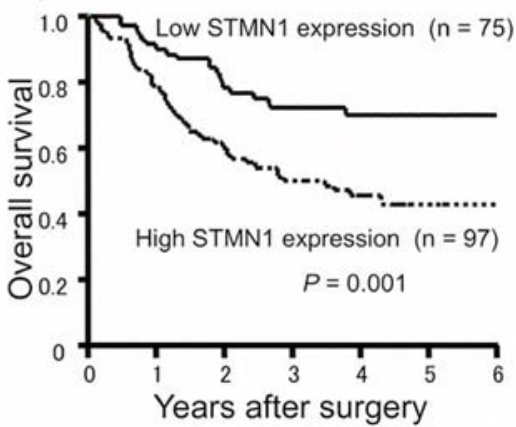

Figure 1. Analysis of the cytoplasmic staining of STMN1 and survival time in surgically resected ESCC. (A) Cytoplasmic STMN1 expression in ESCC and normal esophageal squamous mucosa. (B) High power view of (A). ESCCs with high STMN1 expression invaded the normal esophageal squamous mucosa. (C) Representative section from ESCC showing low STMN1 expression. (D) Representative section from ESCC showing high STMN1 expression. (E) Disease-specific 5-year survival rates for patients with high and low STMN1 expression in ESCC tumors (high, 49.5\%; low, 73.9\%; P=0.002). (F) Overall 5-year survival rates (high, 43.6\%; low, 70.2\%; $\mathrm{P}=0.001$ ). Disease-specific and overall survival rates were significantly lower in ESCC patients with high STMN1 expression.
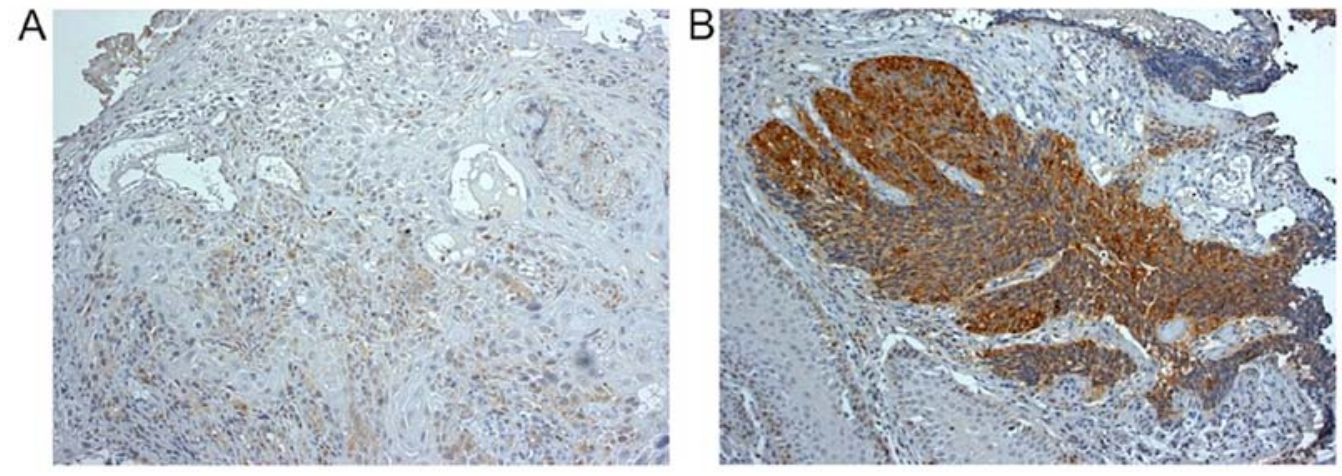

Figure 2. Inverse association of STMN1 expression in pretreatment ESCC biopsy samples with therapeutic efficacy of docetaxel combination CRT. Immunohistochemistry showing the cytoplasmic staining of STMN1 in biopsy specimens before docetaxel combination CRT in (A) a patient with low STMN1 expression and (B) a patient with high STMN1 expression.

Fig. 1F). In univariate analysis, high STMN1 expression was a significant prognostic factor for poor survival $(\mathrm{P}=0.002$; Table II). Multivariate analysis of the six factors significant in univariate analysis showed that high STMN1 expression was an independent risk factor for poor 5-year disease-specific survival ( $\mathrm{RR}=1.339,95 \% \mathrm{CI}, 1.016-1.804, \mathrm{P}=0.038$; Table II).
Inverse association of pretreatment STMN1 expression in ESCC with efficacy of docetaxel combination CRT. STMN1 expression was investigated by immunohistochemistry in 15 biopsy samples obtained before the docetaxel combination CRT. According to the mean STMN1 immunoreactivity score, six ESCC samples (40.0\%) were classified as having low STMN1 
Table II. Univariate and multivariate analysis of clinicopathological factors affecting 5-year disease-specific survival rate following surgery in 172 patients with ESCC.

Univariate analysis

Multivariate analysis

Clinicopathological variables

RR $\quad 95 \% \mathrm{CI} \quad$ P-value

RR $\quad 95 \% \mathrm{CI} \quad$ P-value

Gender (Male/female)

$\begin{array}{lll}0.844 & 0.499-1.266 & 0.445\end{array}$

Age $(<63 />63$ years $)$

0.923

$0.696-1.219$

2.090

$1.602-2.795$

0.574

Depth of tumor invasion (T1-2/T3-4)

2.667

$1.826-4.295$

$<0.001^{\mathrm{a}}$

1.856

$1.446-2.365$

$<0.001^{\mathrm{a}}$

$<0.001^{\mathrm{a}}$

$1.969-17.60$

$<0.001^{\text {a }}$

$1.594-3.752$

$<0.001^{\text {a }}$

2.330

$0.982-3.55$

0.0574

Ki67 labeling index (Low/high)

1.809

1.170-2.066

$0.002^{\mathrm{a}} \quad 1.339$

$-$

1.538

1.548

1.817

1.369

0.970

2.003

1.339

1.171-2.096

$1.190-3.037$

$1.036-1.797$

$0.318-4.625$

$0.977-5.844$

$0.002^{\mathrm{a}}$

$0.004^{\mathrm{a}}$

$0.027^{\mathrm{a}}$

0.962

STMN1 expression (Low/high)

$\mathrm{RR}$, relative risk; $\mathrm{CI}$, confidence interval; ${ }^{\mathrm{a}} \mathrm{P}<0.05$.

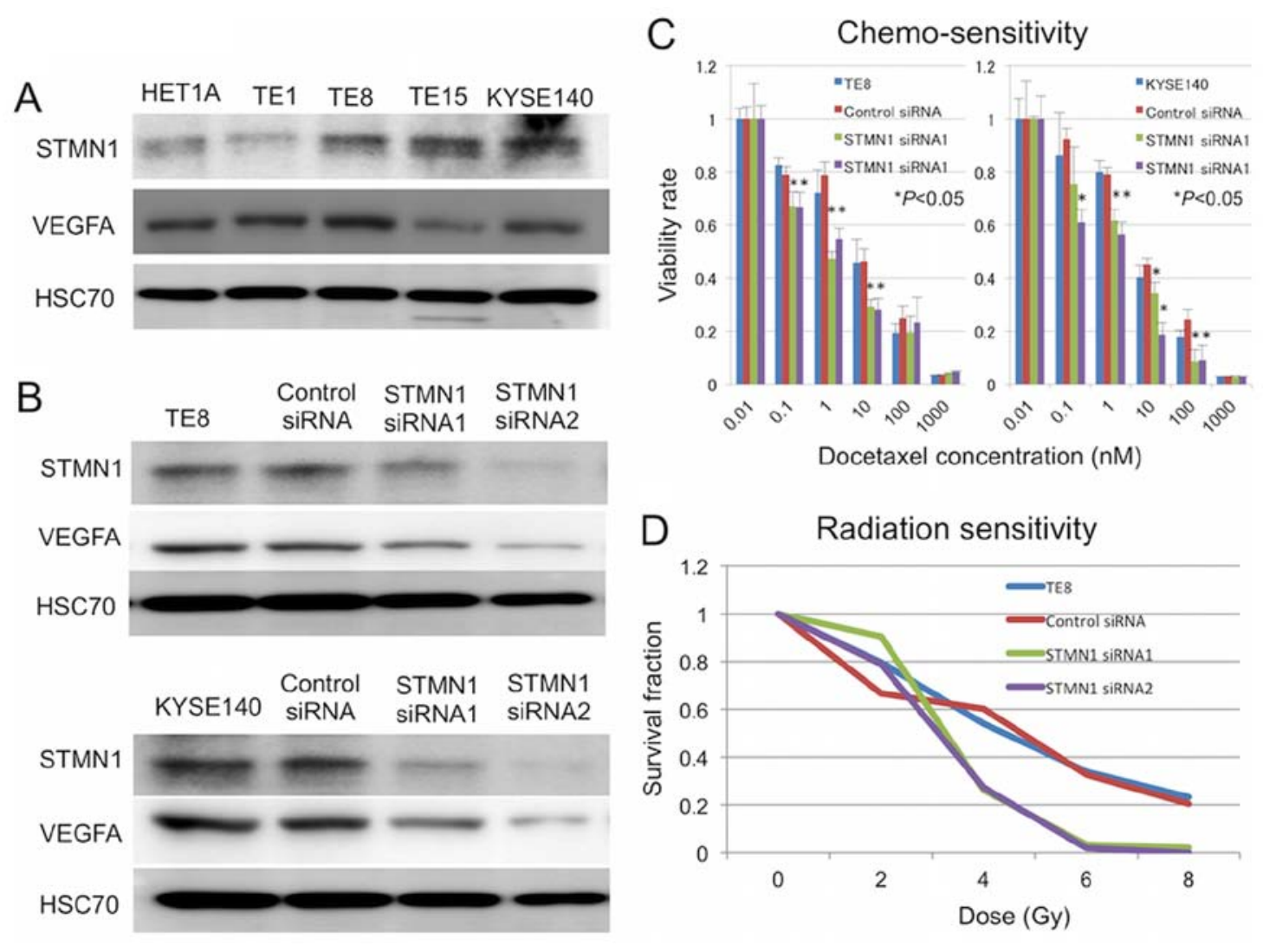

Figure 3. Knockdown of STMN1 expression sensitizes ESCCs to docetaxel and radiation. (A) Differential expression of STMN1 protein in HET1A, TE1, TE8, TE15 and KYSE140 cells as determined by western blotting. HSC70 expression was used as the gel loading control. (B) Western blot analysis showing a marked decrease in STMN1 and VEGF expression levels (band intensities) in lysates from TE-8 and KYSE140 cells transfected with STMN1-specific siRNA compared to those in lysates from untransfected cells and negative control siRNA transfectants. (C) Docetaxel sensitivity in TE8 and KYSE140 cells transfected with STMN1-specific siRNA was determined by WST-8 assay. STMN1-specific siRNA transfectants showed significantly increased sensitivity to docetaxel compared to control transfectants $\left({ }^{*} \mathrm{P}<0.05 ;{ }^{* * *} \mathrm{P}<0.01\right)$. Each point represents the mean \pm SD of triplicate determinations from two independent experiments. (D) Radiation sensitivity in TE8 cells transfected with STMN1 siRNA was evaluated by the colony formation assay. The survival fraction of STMN1-suppressed cells was significantly reduced compared to that of control cells.

expression (Fig. 2A) and nine (60.0\%) as having high STMN1 expression (Fig. 2B). The histological response to neoadjuvant CRT as evaluated from the surgically resected specimens was grade 3 in three patients, grade 2 in six patients, and grade 1 in six patients. Examination of the association of STMN1 expression in biopsy samples with histological response of surgically resected specimens revealed that STMN1 expression was negatively associated with the therapeutic efficacy of 
Table III. STMN1 expression in pretreatment biopsy specimens was inversely associated with the therapeutic efficacy of docetaxel combination CRT.

\begin{tabular}{lccc}
\hline STMN1 & $\begin{array}{c}\text { Pathological } \\
\text { grade 1 }\end{array}$ & $\begin{array}{c}\text { Pathological } \\
\text { grade 2,3 }\end{array}$ & P-value \\
\hline Low expression & 0 & 6 & 0.029 \\
High expression & 6 & 3 & \\
\hline
\end{tabular}

docetaxel combination CRT ( $\mathrm{P}=0.029$; Table III). Six patients had T3 stage and 9 had T4 stage before CRT treatment. After treated by preoperative CRT, 6 patients had grade 1 pathological response, 6 had grade 2 and 3 had grade 3 .

Inhibition of STMN1 expression sensitizes ESCCs to docetaxel in vitro. Several reports have identified STMN1 as a marker for resistance against taxane agents, including in esophageal cancer $(7,19,20,30)$. To determine whether the silencing of STMN1 can increase sensitivity to docetaxel in vitro, TE-8 and KYSE140 cells were transfected with STMN1-specific siRNA, and sensitivity to docetaxel treatment was determined by cell viability assays. Western blotting confirmed a reduction in STMN1 protein expression by $72 \mathrm{~h}$ after transfection (Fig. 3B). Cells transfected with STMN1 siRNA showed significantly higher sensitivity to docetaxel treatment than untreated control cells and control siRNA-transfected cells ( $\mathrm{P}<0.05$; Fig. $3 \mathrm{C})$. The expression of the therapeutic resistance inducible gene VEGF was also lower in STMN1-suppressed cells than control cells (Fig. 3B). Moreover, STMN1 knockdown enhanced the radiation sensitivity of TE-8 and KYSE140 cells (Fig. 3D).

\section{Discussion}

High STMN1 expression was strongly associated with ESCC progression and nuclear Ki-67 accumulation and was an independent prognostic factor for reduced survival in our ESCC cohort without preoperative adjuvant therapies. Moreover, high STMN1 expression in pre-treatment biopsy samples was related to reduced preoperative CRT response. In vitro analysis suggested that STMN1 regulates sensitivity to docetaxel and radiation as well as the induction of the CRT-resistance factor VEGF in ESCCs.

Metastasis resulting from tumor invasiveness is the main cause of death in ESCC patients. In the present study, we immunohistochemically examined STMN1 expression and found that STMN1 was significantly associated with tumor depth, lymph node metastasis, lymphatic invasion, and venous invasion. In a previous study, STMN1 was shown to stimulate cell motility through the extracellular matrix in vitro and to increase the metastatic potential of sarcoma in vivo (31). In addition, Li et al (32) reported that STMN1 promotes epithelial-to-mesenchymal transition by regulating microtubule dynamics. Epithelial-to-mesenchymal transition is thought to be required for the acquisition of metastatic behavior in carcinoma cells, including ESCCs (33). Moreover, STMN1 expression has been linked to PI3K activity and has been suggested as a marker for the activated PI3K signaling pathway (34). Therefore, STMN1 may exert oncogenic functions and contribute to tumor invasiveness. The present study is in agreement with these previous reports demonstrating that STMN1 plays an important role in tumor metastasis and can predict poor prognosis. These findings suggest that STMN1 is a target for new anti-metastatic drugs for ESCC.

Radiation sensitivity increased in STMN1-suppressed cells compared to that in control cells. Radiation resistance in cancer cells is regulated by multiple factors, including hypoxia, receptor tyrosine kinase/Akt, inflammation, DNA damage repair, adhesion pathway and developmental pathway $(35,36)$. Among these factors, we focused on the hypoxia-inducible factor $1, \alpha$ subunit (HIF-1 $\alpha$ )/VEGF pathway because Yoshie et al (37) reported that STMN1 knockdown can suppress this radiation resistance pathway and angiogenesis in human endometrial and endothelial cells, but not in cancer cells. In this study, we confirmed the suppression of VEGF by STMN1 knockdown in ESCCs and found positive associations of STMN1 expression with both venous invasion and lymphatic invasion in surgical ESCC samples. These data are consistent with previous results in non-cancerous cells. Therefore, VEGF suppression by STMN1 knockdown may overcome radiation resistance in ESCC. To the best of our knowledge, this study is the first suggesting that STMN1 can be used as a predictive biomarker for the response to docetaxel combination CRT in clinical ESCC samples.

In conclusion, the present study revealed that high STMN1 expression was a significant factor predicting poor prognosis in ESCC patients. Poor outcomes may result from diminished response to docetaxel combination CRT in ESCCs overexpressing STMN1. The assessment of STMN1 expression in pretreatment biopsy specimens may be a novel strategy to predict ESCC aggression and treatment response against CRT. Our results also strongly suggest that STMN1 is a promising molecular target to overcome CRT resistance in ESCC.

\section{Acknowledgements}

The present study was supported by grants-in-aid for Scientific Research from the Japan Society for the Promotion of Science (JSPS) (grant nos. 26461969, 15K10129 and 15K10085).

\section{References}

1. Jemal A, Bray F, Center MM, Ferlay J, Ward E and Forman D: Global cancer statistics. CA Cancer J Clin 61: 69-90, 2011.

2. Enzinger PC and Mayer RJ: Esophageal cancer. N Engl J Med 349: 2241-2252, 2003.

3. Gebski V, Burmeister B, Smithers BM, Foo K, Zalcberg J and Simes J; Australasian Gastro-Intestinal Trials Group: Survival benefits from neoadjuvant chemoradiotherapy or chemotherapy in oesophageal carcinoma: A meta-analysis. Lancet Oncol 8: 226-234, 2007.

4. Mariette C, Piessen G and Triboulet JP: Therapeutic strategies in oesophageal carcinoma: Role of surgery and other modalities. Lancet Oncol 8: 545-553, 2007.

5. van Hagen P, Hulshof MC, van Lanschot JJ, Steyerberg EW, van Berge Henegouwen MI, Wijnhoven BP, Richel DJ, Nieuwenhuijzen GA, Hospers GA, Bonenkamp JJ, et al; CROSS Group: Preoperative chemoradiotherapy for esophageal or junctional cancer. N Engl J Med 366: 2074-2084, 2012.

6. Rubin CI and Atweh GF: The role of stathmin in the regulation of the cell cycle. J Cell Biochem 93: 242-250, 2004.

7. Alli E, Yang JM, Ford JM and Hait WN: Reversal of stathminmediated resistance to paclitaxel and vinblastine in human breast carcinoma cells. Mol Pharmacol 71: 1233-1240, 2007. 
8. Golouh R, Cufer T, Sadikov A, Nussdorfer P, Usher PA, Brünner N, Schmitt M, Lesche R, Maier S, Timmermans M, et al: The prognostic value of Stathmin-1, S100A2, and SYK proteins in ER-positive primary breast cancer patients treated with adjuvant tamoxifen monotherapy: An immunohistochemical study. Breast Cancer Res Treat 110: 317-326, 2008.

9. Ghosh R, Gu G, Tillman E, Yuan J, Wang Y, Fazli L, Rennie PS and Kasper S: Increased expression and differential phosphorylation of stathmin may promote prostate cancer progression. Prostate 67: 1038-1052, 2007.

10. Xi W, Rui W, Fang L, Ke D, Ping G and Hui-Zhong Z: Expression of stathmin/op18 as a significant prognostic factor for cervical carcinoma patients. J Cancer Res Clin Oncol 135: 837-846, 2009.

11. Kim JY, Harvard C, You L, Xu Z, Kuchenbecker K, Baehner R and Jablons D: Stathmin is overexpressed in malignant mesothelioma. Anticancer Res 27: 39-44, 2007.

12. Jeon TY, Han ME, Lee YW, Lee YS, Kim GH, Song GA, Hur GY, Kim JY, Kim HJ, Yoon S, et al: Overexpression of stathmin1 in the diffuse type of gastric cancer and its roles in proliferation and migration of gastric cancer cells. Br J Cancer 102: 710-718, 2010

13. Kang W, Tong JH, Chan AW, Lung RW, Chau SL, Wong QW, Wong N, Yu J, Cheng AS and To KF: Stathmin1 plays oncogenic role and is a target of microRNA-223 in gastric cancer. PLoS One 7: e33919, 2012

14. Hsieh SY, Huang SF, Yu MC, Yeh TS, Chen TC, Lin YJ, Chang CJ, Sung CM, Lee YL and Hsu CY: Stathmin1 overexpression associated with polyploidy, tumor-cell invasion, early recurrence, and poor prognosis in human hepatoma. Mol Carcinog 49: 476-487, 2010.

15. Trovik J, Wik E, Stefansson IM, Marcickiewicz J, Tingulstad S, Staff AC, Njolstad TS; MoMaTec Study Group, Vandenput I and Amant F: Stathmin overexpression identifies high-risk patients and lymph node metastasis in endometrial cancer. Clin Cancer Res 17: 3368-3377, 2011.

16. Zheng P, Liu YX, Chen L, Liu XH, Xiao ZQ, Zhao L, Li GQ, Zhou J, Ding YQ and Li JM: Stathmin, a new target of PRL-3 identified by proteomic methods, plays a key role in progression and metastasis of colorectal cancer. J Proteome Res 9: 4897-4905, 2010.

17. Lin WC, Chen SC, Hu FC, Chueh SC, Pu YS, Yu HJ and Huang KH: Expression of stathmin in localized upper urinary tract urothelial carcinoma: Correlations with prognosis. Urology 74: 1264-1269, 2009.

18. Akhtar J, Wang Z, Yu C, Li CS, Shi YL and Liu HJ: STMN-1 is a potential marker of lymph node metastasis in distal esophageal adenocarcinomas and silencing its expression can reverse malignant phenotype of tumor cells. BMC Cancer 14: 28, 2014.

19. Wang R, Dong K, Lin F, Wang X, Gao P, Wei SH, Cheng SY and Zhang HZ: Inhibiting proliferation and enhancing chemosensitivity to taxanes in osteosarcoma cells by RNA interference-mediated downregulation of stathmin expression. Mol Med 13: 567-575, 2007.

20. Feng W, Xiaoyan X, Xuan Y, Xiangke L, Zichang Y, Ran Z, Liuxing W and Qingxia F: Silencing stathmin-modulating efficiency of chemotherapy for esophageal squamous cell cancer with paclitaxel. Cancer Gene Ther 22: 115-121, 2015.

21. Thallinger CM, Raderer M and Hejna M: Esophageal cancer: A critical evaluation of systemic second-line therapy. J Clin Oncol 29: 4709-4714, 2011

22. Pasini F, de Manzoni G, Pedrazzani C, Grandinetti A, Durante E, Gabbani M, Tomezzoli A, Griso C, Guglielmi A, Pelosi G, et al: High pathological response rate in locally advanced esophageal cancer after neoadjuvant combined modality therapy: Dose finding of a weekly chemotherapy schedule with protracted venous infusion of 5-fluorouracil and dose escalation of cisplatin, docetaxel and concurrent radiotherapy. Ann Oncol 16: 1133-1139, 2005 .
23. Okumura H, Uchikado Y, Setoyama T, Matsumoto M, Owaki T, Ishigami $\mathrm{S}$ and Natsugoe $\mathrm{S}$ : Biomarkers for predicting the response of esophageal squamous cell carcinoma to neoadjuvant chemoradiation therapy. Surg Today 44: 421-428, 2014.

24. Zhang X, Ji J, Yang Y, Zhang J and Shen L: Stathmin1 increases radioresistance by enhancing autophagy in non-small-cell lung cancer cells. Onco Targets Ther 9: 2565-2574, 2016.

25. Sobin LH and Wittekind CW: TNM Classification of Malignant Tumours. 6th edition. John Wiley \& Sons, Hoboken, NJ, 2002.

26. Fukuchi M, Fukai Y, Sohda M, Miyazaki T, Nakajima M, Inose T, Tanaka N, Tsukada K, Kato H and Kuwano H: Expression of the prolyl isomerase Pin1 is a useful indicator of sensitivity to chemoradiotherapy in advanced esophageal squamous cell carcinoma. Oncol Rep 21: 853-859, 2009.

27. Suzuki S, Miyazaki T, Tanaka N, Sakai M, Sano A, Inose T, Sohda M, Nakajima M, Kato $\mathrm{H}$ and Kuwano H: Prognostic significance of CD151 expression in esophageal squamous cell carcinoma with aggressive cell proliferation and invasiveness. Ann Surg Oncol 18: 888-893, 2011.

28. Singer S, Ehemann V, Brauckhoff A, Keith M, Vreden S, Schirmacher P and Breuhahn K: Protumorigenic overexpression of stathmin/Op18 by gain-of-function mutation in p53 in human hepatocarcinogenesis. Hepatology 46: 759-768, 2007.

29. Japanese Society for Esophageal Diseases: Guidelines for the Clinical and Pathological Studies on Carcinoma of the Esophagus. 10th edition. Kanehara, 2007.

30. Watanabe A, Suzuki H, Yokobori T, Altan B, Kubo N, Araki K, Wada S, Mochida Y, Sasaki S, Kashiwabara K, et al: Forkhead box protein $\mathrm{C} 2$ contributes to invasion and metastasis of extrahepatic cholangiocarcinoma, resulting in a poor prognosis. Cancer Sci 104: 1427-1432, 2013.

31. Belletti B, Nicoloso MS, Schiappacassi M, Berton S, Lovat F, Wolf K, Canzonieri V, D'Andrea S, Zucchetto A, Friedl P, et al: Stathmin activity influences sarcoma cell shape, motility, and metastatic potential. Mol Biol Cell 19: 2003-2013, 2008.

32. Li N, Jiang P, Du W, Wu Z, Li C, Qiao M, Yang X and Wu M: Siva1 suppresses epithelial-mesenchymal transition and metastasis of tumor cells by inhibiting stathmin and stabilizing microtubules. Proc Natl Acad Sci USA 108: 12851-12856, 2011.

33. Yokobori T, Suzuki S, Tanaka N, Inose T, Sohda M, Sano A, Sakai M, Nakajima M, Miyazaki T, Kato H, et al: MiR-150 is associated with poor prognosis in esophageal squamous cell carcinoma via targeting the EMT inducer ZEB1. Cancer Sci 104: 48-54, 2013.

34. Salvesen HB, Carter SL, Mannelqvist M, Dutt A, Getz G, Stefansson IM, Raeder MB, Sos ML, Engelsen IB, Trovik J, et al: Integrated genomic profiling of endometrial carcinoma associates aggressive tumors with indicators of PI3 kinase activation. Proc Natl Acad Sci USA 106: 4834-4839, 2009.

35. Kim BM, Hong Y, Lee S, Liu P, Lim JH, Lee YH, Lee TH, Chang KT and Hong Y: Therapeutic implications for overcoming radiation resistance in cancer therapy. Int J Mol Sci 16: 26880-26913, 2015.

36. Vaupel P, Thews $\mathrm{O}$ and Hoeckel M: Treatment resistance of solid tumors: Role of hypoxia and anemia. Med Oncol 18: 243-259, 2001.

37. Yoshie M, Miyajima E, Kyo S and Tamura K: Stathmin, a microtubule regulatory protein, is associated with hypoxia-inducible factor-1alpha levels in human endometrial and endothelial cells. Endocrinology 150: 2413-2418, 2009. 